University of Wollongong

Research Online

Faculty of Engineering and Information

Faculty of Engineering and Information

Sciences - Papers: Part A

Sciences

2016

Investigation of the effect of electrolytic hydrogen charging of X70 steel: II. Microstructural and crystallographic analyses of the formation of hydrogen induced cracks and blisters

\author{
Ahmed A. Saleh \\ University of Wollongong, asaleh@uow.edu.au \\ Daniel Hejazi \\ University of Wollongong, dh712@uowmail.edu.au \\ Azdiar A. Gazder \\ University of Wollongong, azdiar@uow.edu.au \\ Druce P. Dunne \\ University of Wollongong, druce@uow.edu.au \\ Elena V. Pereloma \\ University of Wollongong, elenap@uow.edu.au
}

Follow this and additional works at: https://ro.uow.edu.au/eispapers

Part of the Engineering Commons, and the Science and Technology Studies Commons

Research Online is the open access institutional repository for the University of Wollongong. For further information contact the UOW Library: research-pubs@uow.edu.au 


\title{
Investigation of the effect of electrolytic hydrogen charging of X70 steel: II. Microstructural and crystallographic analyses of the formation of hydrogen induced cracks and blisters
}

\author{
Abstract \\ Hydrogen-induced cold cracking and blistering in hydrogen-charged X70 steel was found to be highly \\ dependent on microstructure, with the banded ferrite-pearlite microstructure of hot rolled strip showing a \\ higher susceptibility than other microstructures produced by different thermal-mechanical routes. \\ Although crack initiation was particularly sensitive to microstructure, crack growth occurred largely \\ parallel to the rolling plane, at least at a macroscopic level, for all of the microstructures investigated. The \\ crack plane was associated with structural anisotropy arising from processing by rolling and was not \\ found to be related to a preferred grain orientation. At a microstructural level, crack propagation was \\ mostly transgranular and occurred dominantly along slip planes of the ferrite grains. Cracks were initiated \\ at strong traps in the microstructure when the hydrogen and local stress concentrations reached critical \\ levels for hydrogen-induced fracture. The main initiation sites were coarse inclusions, mainly oxides, and \\ ferrite-pearlite interfaces. \\ Disciplines \\ Engineering | Science and Technology Studies \\ Publication Details \\ Saleh, A. A., Hejazi, D., Gazder, A. A., Dunne, D. P. \& Pereloma, E. V. (2016). Investigation of the effect of \\ electrolytic hydrogen charging of X70 steel: II. Microstructural and crystallographic analyses of the \\ formation of hydrogen induced cracks and blisters. International Journal of Hydrogen Energy, 41 (28), \\ 12424-12435.
}

This journal article is available at Research Online: https://ro.uow.edu.au/eispapers/6226 


\title{
Investigation of the effect of electrolytic hydrogen charging of X70 steel:
}

\section{Microstructural and crystallographic analyses of the formation of hydrogen induced} cracks and blisters

\author{
A.A. Saleh ${ }^{1}$, D. Hejazi ${ }^{1}$, A.A. Gazder ${ }^{2}$, D.P. Dunne ${ }^{1}$ E.V. Pereloma ${ }^{1,2^{*}}$ \\ ${ }^{1}$ School of Mechanical, Materials and Mechatronic Engineering, University of Wollongong, \\ NSW 2522, Australia \\ ${ }^{2}$ Electron Microscopy Centre, University of Wollongong, NSW 2500, Australia
}

\begin{abstract}
Hydrogen-induced cold cracking and blistering in hydrogen-charged X70 steel was found to be highly dependent on microstructure, with the banded ferrite-pearlite microstructure of hot rolled strip showing a higher susceptibility than other microstructures produced by different thermal-mechanical routes. Although crack initiation was particularly sensitive to microstructure, crack growth occurred largely parallel to the rolling plane, at least at a macroscopic level, for all of the microstructures investigated. The crack plane was associated with structural anisotropy arising from processing by rolling and was not found to be related to a preferred grain orientation. At a microstructural level, crack propagation was mostly transgranular and occurred dominantly along slip planes of the ferrite grains. Cracks were initiated at strong traps in the microstructure when the hydrogen and local stress concentrations reached critical levels for hydrogen-induced fracture. The main initiation sites were coarse inclusions, mainly oxides, and ferrite-pearlite interfaces.
\end{abstract}

Keywords: X70 pipeline steel, electrolytic hydrogen charging, hydrogen-induced cold cracking (HICC), effect of microstructure, crystallography of cracking, effect of grain texture.

* Corresponding author:

E.V. Pereloma

Phone: +612 42215507 Fax: +612 42213662 E-mail: elenap@uow.edu.au 


\section{Introduction}

The presence of even small concentrations (ppm) of hydrogen atoms can be detrimental to the mechanical properties of pipeline steels as it promotes hydrogen-induced cold cracking (HICC), which is a form of hydrogen embrittlement (HE). This detrimental effect is due to the high mobility of hydrogen atoms at ambient temperatures which leads to build-up of hydrogen at stress concentration sites associated with microstructural features such as inclusions and grain/phase boundaries [1].

Since diffusible hydrogen is necessary for HICC, a large number of studies have been conducted with the aim of increasing the density of hydrogen traps in the steel microstructure to trap diffusible hydrogen and reduce the likelihood of HICC [2-5]. Trapping sites can be considered to be either reversible (weak) or irreversible (strong) [6, 7].

Crack initiation occurs on a micro-scale and the localised crack path can potentially involve intergranular fracture along ferrite or ferrite/pearlite grain boundaries; or transgranular fracture on either cleavage or slip planes of the ferrite. The related micro-mechanisms of crack propagation are usually classified as either microvoid coalescence (MVC) or quasicleavage (QC). MVC is associated with enhanced localised plasticity (slip) which results in formation of voids or dimples that link together and subsequently lead to crack growth. In contrast, QC involves the accumulation of areal segments of fracture that occur in a brittle manner, typically on cleavage planes. Separately nucleated segments or facets can then link together by fracture steps or by narrow bridges formed by MVC [8]. The fracture facets can be associated with embrittling microstructural features such as large inclusions, which act as fracture acceleration sites when they are located in a region of high stress concentration ahead of an advancing crack.

There is abundant evidence that hydrogen can promote both cleavage fracture and local ductile failure by void formation and coalescence in the same steel, depending on the local conditions in the stress concentrated zone ahead of a newly initiated or established crack. This "flexibility" of hydrogen in degrading the resistance of a material to fracture is a concept advanced by Beachem [9] who considered that hydrogen can promote cracking by the mechanism that the material is most susceptible to. Since microstructure can be described as an "irregular continuum", the local microscopic features ahead of a crack tip will be variable, 
as will be the "easiest" fracture mechanism. Therefore, mixed mode fracture is expected to be the norm for HICC.

In relation to the initiation of cracking and cavity development, Ren et al. [10] proposed a formation mechanism that involves the aggregation of hydrogen atoms and vacancies at trapping sites to form a "blister nucleus", followed by cracking at the edges of the cavity when the internal hydrogen pressure and the stress concentration produce a "nucleus" of critical size. Several publications [10-14] have shown that second phase particles are the most common nucleation sites for cracks that result in the formation of internal cavities.

To this end, while much research has been conducted on the response of different steels to hydrogen charging, the present study is one of the first investigations to report on the response of different microstructures in the same X70 steel subjected to varying types of thermal and thermomechanical treatments. It is noted that while Mohtadi-Bonab et al. [15] have recently investigated different X70 steel microstructures subjected to water-quenching and water-spraying treatments, the microstructures produced in the present study are different to those obtained in Ref. [15] and more likely to be relevant to actual pipeline microstructures.

The samples and microstructures investigated here are as follows: (i) as-rolled (AR) strip with a banded ferrite-pearlite (BFP) microstructure; (ii) transfer bar (TB) with a nearly equiaxed ferrite-granular bainite (FGB) microstructure, (iii) normalised and annealed TB samples with equiaxed ferrite-pearlite (EFP) microstructures with different average ferrite grain sizes; and (iv) a simulated coarse grained heat affected zone (CGHAZ) with a bainitic ferrite $(\mathrm{BF})$ microstructure.

In Part I of this research work (see Ref. [16]), the effect of these microstructural changes on hydrogen uptake, HICC and blistering were examined. It was confirmed that the accumulation of hydrogen at trapping sites within the steel during electrolytic charging, in the absence of externally applied stress, led to the formation of micro-cracks within the samples and to blisters on the surface. For the electrolytic charging conditions used in the current investigation, the susceptibility to HICC and blistering was found to be highly microstructure-dependent, with the BFP microstructure exhibiting the highest susceptibility and the BF microstructure showing no evidence of cracking or blistering. 
Therefore, the present paper is focused mainly on the cracked BFP, FGB and EFP microstructures, with limited discussion of the crack-free BF microstructure. The formation and propagation of HICC has been examined for microstructures with differing phases and morphologies, as well as level of structural refinement. In particular, detailed electron backscattering diffraction (EBSD) analysis has been conducted on crystallographic aspects of the crack path and the ferrite grains through which cracking occurred.

\section{Experimental methods}

The X70 steel used in this study was received from BlueScope Steel Ltd. Full details of the steel composition determined using optical emission spectroscopy are given in Ref. [16], but the most significant alloying elements of the X70 steel are: C (0.074 wt\%), Mn (1.14 wt\%), Si (0.22 wt\%), Mo (0.1 wt\%) and Nb (0.06 wt\%). Further, the S content was $0.002 \mathrm{wt} \%$ (20 ppm), which is at the lower end of the normal range for structural/pipeline steels. All thermomechanical processing details of the AR strip (BFP microstructure), TB (FGB microstructure) and normalised/annealed TB (EFP microstructure) samples are given in Ref. $[16]$.

Hydrogen charging was carried out using a current density of $50 \mathrm{~mA} / \mathrm{cm}^{2}$ in $0.5 \mathrm{~N} \mathrm{H}_{2} \mathrm{SO}_{4}$ with $250 \mathrm{mg} / \mathrm{L}$ of $\mathrm{NaAsO}_{2}$. Measurement of the diffusible hydrogen content was performed by the standard mercury method at ambient temperature. The total hydrogen content was measured using an ELTRA ONH-2000 instrument, which analyses the gases evolved from a fused sample. The use of these two techniques enabled the determination of the total hydrogen content, the diffusible hydrogen content and, by difference, the concentration of residual (strongly trapped) hydrogen.

Microstructures were examined using both optical and scanning electron microscopy. Compositional analysis of precipitate particles and inclusions was conducted using an XMax Oxford Instruments Energy Dispersive X-Ray Spectroscopy detector on a JEOL 7001F Field Emission Gun- Scanning Electron microscope (FEG-SEM).

Samples for microscopy and for EBSD examination were prepared by standard metallographic methods which included polishing up to the colloidal silica stage and light etching in $2 \%$ Nital solution. 
In order to study the crystallography of HICC in the samples investigated, EBSD was conducted on the same FEG-SEM using a Nordlys-II(S) EBSD detector and the Oxford Instruments AZtec acquisition software suite, and operating at $15 \mathrm{kV}$, and $\sim 5 \mathrm{nA}$, with a 24 mm working distance. A step size of $0.15 \mu \mathrm{m}$ was maintained constant for all samples.

Post-processing of the EBSD data was undertaken using the Oxford Instruments - Channel $5^{\mathrm{TM}}$ software package. The EBSD maps were first cleaned by removing wild orientation spikes, extrapolating zero solutions using a minimum of 6 neighboring pixels.

In all EBSD maps, a minimum of 3 pixels was used to identify subgrain/grain structures and misorientations $(\theta)$ less than $2^{\circ}$ were disregarded. Low angle grain boundaries (LAGBs) are defined as those within the range $2^{\circ} \leq \theta<15^{\circ}$, whereas high angle grain boundaries (HAGBs) are considered to correspond to $\theta \geq 15^{\circ}$. The maximum tolerance of the misorientation angle $(\Delta \theta)$ for coincidence site lattice (CSL) boundaries was identified by the Brandon criterion (i.e., $\Delta \theta \leq 15^{\circ} \Sigma^{-1 / 2}$ ) [17].

Trace analysis of the EBSD maps was performed in order to determine the potential transgranular crack propagation planes among the $\{001\}$ cleavage planes and the $\{110\}$, $\{112\}$ and $\{123\}$ slip planes $[18,19]$. Firstly the angle between the crack trace in a grain and the map horizontal (transverse direction (TD)) was measured. Then the orientation of the cracked grain was used to calculate the angles between the traces of all the potential planes and the map horizontal direction. The plane that returned the closest match with the measured crack trace angle was selected to be the most likely crack propagation plane in the grain under consideration. When two planes returned similar match, equal probability was assigned to both.

It is highlighted that, while the above trace analysis procedure has been effectively used in several EBSD investigations (e.g. Refs. [18-22]), it inherently assumes that the crack plane is perpendicular to the examined two-dimensional planar surface. A more precise identification of the crack planes requires three-dimensional analysis (by serial sectioning for example), however, this is beyond the scope of the present study.

\section{Results}




\subsection{Microstructure characterisation}

Figures 1 to 6 consist of SEM micrographs (Figures 1, 3, 5 and 6) and selected EDS results for inclusions/precipitates (Figures 2 and 4) associated with hydrogen induced cracking of the investigated microstructural conditions.

Figure 1 shows micrographs of the BFP microstructure (RD-ND section) after electrolytic charging for 3 hours. It is evident from these micrographs that hydrogen charging resulted in internal cracks and surface blisters. Figure 1(a) shows a blister and some cracks formed close to the surface at the edge of the blister. In addition, a long crack, parallel to $\mathrm{RD}$, is present at a depth of $\sim 150 \mu \mathrm{m}$ from the surface. When cracking extended to the surface it was typically observed to emerge near the perimeter of the blister, probably because the higher stress concentration around the rim of the blister influences the crack path (see also Figures 8, 9 and 11(a) of Ref. [16]).

Figures 1(b-d) are magnified images of the long crack shown in Figure 1(a), which has propagated along a ferrite-pearlite interface of the banded microstructure. Figure 1(b) also shows crack propagation across pearlite colonies. Similar observations have been reported by Albarran et al. [23], Lee and Chan [24] for BFP microstructures. Three particles lying along or close to the crack path are also indicated by white arrows in Figures 1(c) and (d). EDS analysis of the two particles in Figure 1(d) indicated that they are Nb- and Ti-rich and are therefore likely to be NbTi carbonitrides. Although these two particles do not actually lie on the crack path, there is a clearer association between the crack path and the larger particle shown in Figure 1(c), which was also identified as a TiNb-rich carbonitride (Figure 2). This link with cracking is more likely to be as a fracture acceleration site than a crack initiator, as $\mathrm{Nb}$ and Ti carbonitrides have a lower potential for hydrogen trapping and crack initiation than oxides and oxysulphides [25].

Another example of HICC under a surface blister is shown in Figure 3 for the EFP microstructure (RD-ND section) after electrolytic charging for 3 hours. The blister and the large open crack below it are clearly visible in Figure 3(a), as are stepwise cracks extending to the surface at the edges of the blister. This type of cracking is a response to localised stress concentration around the periphery of the blister which promotes crack growth along planes other than the rolling plane. Eventually, when the cracks become surface breaking, hydrogen effusion occurs accompanied by stress relaxation. Figure 3(b) is a magnified image of the 
large void that formed under the blister. An inclusion marked with an arrow is also present close to the crack.

Figure 3(c) shows a large inclusion ( $10 \mu \mathrm{m}$ in diameter) located within a crack, at the site of branching into two cracks, approximately normal to each other. EDS analysis of this inclusion and other nearby inclusions indicated that they are oxides of $\mathrm{Al}$ and Ca (Figure 4). This observation is consistent with the results reported by Dong et al. [26] on the capacity of Ca-Al oxides to act as initiation sites for HICC in hydrogen charged X70 steel. Interfacial decohesion is likely to have occurred around the large particle shown in Figure 3(c), followed by crack extension in three main directions due the stress state around the particle. Crack growth away from the particle is also indicated by the narrowing of each of the three crack segments with distance from the particle.

Figure 5 records SEM micrographs of the FGB microstructure (RD-ND section) after electrolytic charging for 17 hours. Blistering for this microstructure was substantially delayed compared to the BFP and EFP microstructures described above. However, blistering did occur after 17 hours of charging and an example is given in Figure 5(a) which shows a small blister with underlying hydrogen-induced cracks. Ferrite morphologies in the present FGB microstructure comprise quasi-polygonal grains and lath-like regions. Cracking proceeded transgranularly across both of these ferrite morphologies, as well as intergranularly along boundaries between laths or interfaces between laths and quasi-polygonal ferrite grains. The crack highlighted with a white arrow in Figure 5(b) appears to have started from an inclusion, which was identified by EDS as an oxide of $\mathrm{Al}$ and $\mathrm{Ca}$.

As discussed in Ref. [16], the residual hydrogen content after charging of the FGB microstructure was relatively low due to the high density of reversible traps, such as dislocations and grain/lath boundaries, which distribute the hydrogen atoms more homogeneously throughout the structure and reduce the probability of the development of a critical hydrogen concentration at potential crack-initiation sites. Cracking, pressure build-up and blister formation are thereby delayed.

\subsection{Electron back-scattering diffraction analysis}

Since the EBSD technique delineates grains based on their crystallographic orientation, it allows unambiguous identification of the crack propagation mode (intergranular versus transgranular). Figure 7 provides representative inverse pole figure (IPF) maps of cracked 
regions of: the BFP microstructure (Figure 7(a)), the FGB microstructure (Figure 7(b)), and the EFP microstructure (Figure 7(c)). As seen in Figures 7(a-c), the cracks predominantly follow transgranular paths with only a limited incidence of intergranular propagation ${ }^{1}$. Figure 7(d) is an IPF map of the crack-free BF (simulated CGHAZ) microstructure, which shows orientation contrast for the various packets of bainitic ferrite laths.

The misorientation distribution of the different microstructures is shown in Figure 8(a), with the area fraction of LAGBs and length fraction of CSL boundaries given in Figures 8(b) and (c), respectively. The LAGB area fraction given in Figure 8(b) was calculated based on $5^{\circ} \leq$ $\theta \leq 15^{\circ}$ in order to negate the effect of the LAGBs induced by the strain fields around the crack edge (subgrains). It is well known that LAGBs and CSL boundaries provide higher resistance to intergranular crack propagation due to their lower energy compared to random HAGBs [18, 27]. However, the observation of dominant transgranular crack propagation indicates that crack arrest or retardation by LAGBs and CSL boundaries was rather marginal in the present microstructures. Moreover, the length fractions of the CSL boundaries was generally small in all of the investigated microstructures (Figure 8(c)).

An alternative effect of LAGBs arises from their propensity to act as reversible hydrogen traps [28-30]. In this regard, the relatively high fraction of LAGBs (Figure 8(b)) in the BF (simulated CGHAZ) microstructure is likely to contribute to the suppression of blistering/cracking in this case. The significant dislocation substructure of the bainitic ferrite together with the LAGBs can act as weak reversible traps that promote a more homogeneous distribution of hydrogen, thereby impeding build-up of critical hydrogen concentrations at sites of stress concentration which can initiate cracking. This hypothesis is consistent with the low residual hydrogen content measured for the BF microstructure [16].

Following the trace analysis procedure described in Section 2, the fraction of various crack planes observed in the different microstructures was estimated, see Table 2. Transgranular cracking propagated along the $\{001\}$ cleavage planes and also along the $\{110\},\{112\}$ and $\{123\}$ slip planes, without a clear preferential trend towards a specific plane. Branches of the hydrogen-induced cracks also propagated transgranularly along the same crystallographic planes. As seen in Table 2, 22\%, 30\% and 10\% of the cracks in the BFP, FGB and EFP microstructures occurred by cleavage on $\{100\}$ planes. However, if the fractions of the

\footnotetext{
${ }^{1}$ It should be noted that intergranular crack propagation along ferrite-pearlite interfaces was also observed in RD-ND sections of the BFP microstructure (see Figures 1 and 2).
} 
$\{110\},\{112\}$ and $\{123\}$ slip planes are combined, fracture along slip planes is the dominant mode of fracture in the three investigated microstructures. Crack propagation along slip planes was particularly high for the EFP microstructure (90\%), indicating that the heat treatment may have increased the cleavage resistance of this microstructure.

In order to examine whether or not a specific crack propagation plane was associated with a preferred grain orientation, the orientations of grains exhibiting $\{001\},\{110\},\{112\}$ and $\{123\}$ crack propagation planes were examined in all three microstructures. The compiled results are plotted on (110) pole figures in Figure 9. Examination of the local grain orientations collectively in the BFP, FGB and EFP microstructures revealed that there was no orientation clustering along the crack paths. This indicates that the grain orientation did not have a significant effect on the crack propagation path observed in the present study. In other words, grains with a crack plane of the same crystallographic form were not associated with a preferred crystallographic orientation, as the distribution of the $\{110\}$ poles shown in each of Figures 9(a-d) is essentially random. This result indicates that the crystallography of the crack plane through a specific grain was not associated with a preferred grain orientation, but was determined by the most appropriately aligned slip or cleavage plane of the grain to allow easiest propagation of cracking, within the overall constraint of macroscopic cracking approximately parallel to the rolling plane.

\section{Discussion}

\subsection{Severity of hydrogen-induced cracking}

The relative severity of cracking in the BFP, FGB and EFP microstructures was determined previously [16] using the NACE procedure for assessment of the susceptibility of pipeline steels to hydrogen-induced stress corrosion cracking [31]. Cracks are analysed in one or both of two mutually perpendicular cross-sections: Section A (which contains the rolling direction (RD) and the normal direction (ND)); and Section B (which contains the transverse direction (TD) and ND), see Figure 1, Ref. [16]. Three ratios can be determined: (i) the crack sensitivity ratio (CSR), which is a measure of the total crack-affected area; (ii) the crack length ratio (CLR), which is a measure of the total crack length parallel to $\mathrm{RD}$ in the RD-ND section and parallel to TD in the TD-ND section; and (iii) the crack thickness ratio (CTR), which is a measure of the spread of cracking by deviation of the direction of cracking from 
$\mathrm{RD}$ in the RD-ND section or TD in the TD-ND section. The results for measurements of these ratios in the two transverse sections are given in Table 7 of Ref. [16] and are summarised here in Table 1.

The measurements given in Table 1 are relevant to the macroscopic form of the hydrogeninduced cracks and this aspect is covered in detail in Ref. [16]. However, the ratios are also referred to, where relevant, in the current paper.

\subsection{Effect of grain size on cracking}

Figure 3 shows a blister detected in the EFP microstructure with an average ferrite grain size of $14 \mu \mathrm{m}$. In order to investigate the effect of grain size on cracking and blistering, SEM micrographs were also obtained (Figure 6) from an EFP microstructure (RD-ND section) with an average ferrite grain size of $46 \mu \mathrm{m}$. EDS analysis of the large inclusion highlighted with a white arrow in Figure 6(d) revealed that it contained Al, Mn, Ca, Fe and S, suggesting a mixed-compound inclusion consisting of an Al-Ca oxide and an Fe-Mn sulphide.

For an average grain size of $120 \mu \mathrm{m}$, surface blisters were rare, indicating that extensive grain boundaries perpendicular to the surface provide hydrogen migration paths to the surface where effusion occurs. Since these extended hydrogen migration paths are largely unavailable for the finer-grained EFP microstructures, the subsurface cracking occurring in these cases is mainly parallel to the rolling plane.

Additionally, it is clear that high temperature annealing for a long period attenuates the banded nature of the microstructure inherited from hot rolling, thereby reducing the susceptibility to HICC.

\subsection{Effect of grain shape on cracking}

Hot rolled steels typically show some elongation of ferrite grains in both the rolling and transverse directions [32]. The grain shape approximates an oblate spheroid that generates elliptical grain shapes in the RD-ND and TD-ND cross-sections. The ellipticity is often described in terms of an elongation ratio (ER), which is defined as $d_{R D} / d_{N D}$ or $d_{T D} / d_{N D}$, where $\mathrm{d}$ is the grain "diameter" measured parallel to $\mathrm{ND}$ and $\mathrm{RD}$, or $\mathrm{TD}$, in the 2-dimensional 
section. The elongation ratio is typically higher in the RD-ND section because of the plane strain nature of the rolling process.

EBSD was used in the current work to provide a different measure of the grain shape; the grain shape factor (GSF). GSF is based on a best-fit ellipse model for grain shape in a 2dimensional section [33]:

$$
G S F=\frac{1}{n} \sum_{i=1}^{n} \cos ^{2} \Omega_{i}
$$

This equation defines GSF in terms of the average angle $(\Omega)$ between the horizontal direction (parallel to TD in the TD-ND cross-section map) and the major axis of an assumed elliptical grain (see the schematic inset in Figure 10).

For $\Omega=0^{\circ}$ or $180^{\circ}, G S F=1$ and the major axis of the fitted ellipse is parallel to TD; and for $\Omega=90^{\circ}, G S F=0$, and the major axis of the ellipse is parallel to ND.

The distributions of measured $\Omega$ angles for the BFP, FGB and EFP microstructures are shown in Figure 10. It is evident from this figure that the EFP microstructure showed a relatively uniform distribution of $\Omega$ angles, whereas the BFP structure showed that grains elongated in TD were more common. In contrast, the FGB sample showed spikes in the distribution of $\Omega$ angles (at $\sim 90^{\circ}$ ) that were approximately perpendicular to TD (parallel to ND).

The values of GSF corresponding to the three microstructures reflect the angular distributions shown in Figure 10; BFP (0.62), FGB (0.44) and EFP (0.55). The orientation of the hydrogen-induced cracks in the same TD-ND cross-section (Section B) can be connected to the ferrite grain shape via the GSF values. The BFP microstructure exhibits the highest GSF value as more grains are aligned parallel to TD which, in turn, is associated with the highest CLR value (i.e., long cracks parallel to TD). Even higher GSF values would be expected for Section A (the RD-ND cross-section) because of ferrite grain anisotropy arising from the distribution of precipitates and inclusions generated by the plane strain condition applying during hot rolling.

The quasi-polygonal FGB microstructure showed a relatively low GSF value and would therefore be expected to allow crack propagation perpendicular to TD, leading to a relatively high CTR value (i.e., cracks that tend to deflect towards the surface). The excessively high 
values of CTR in Table 1 are due to the small sample thickness, as discussed in Ref. [16], but the relative values should be significant.

Comparing the Section B values for CSR in Table 1, the BFP microstructure showed the highest ratio, consistent with the highest GSF value. The lower cracking sensitivity ratios and GSF values for the EFP and FGB microstructures suggest that thermal-mechanical treatments other than, or in addition to, hot rolling of strip could improve the overall cracking resistance of the X70 steel.

The current experimental correlations between the GSF and the crack severity parameters mainly relate to dominant transgranular HICC without an externally applied stress. Interestingly, Arafin et al. [33] reported similar observations during their combined experimental and Monte Carlo simulation study of the intergranular stress corrosion cracking behaviour in API 5L X65 pipeline steel. Considering the present results with those in Ref. [33] underscores the importance of grain shape control, regardless of the dominant crack propagation mode and the absence or presence of external stress.

\subsection{Crack propagation mode}

While Figures 7(a-c) revealed predominant transgranular crack propagation paths, previous EBSD studies of HICC in API-5L-X46 and ASME-A106 grade B pipeline steels reported predominant intergranular crack propagation [19, 22]. Bruemmer et al. [34] claimed that the transition from intergranular to transgranular HICC in iron alloys is related to the sulphur concentration at the grain boundaries. However, segregation of solute $\mathrm{S}$ to grain boundaries is more likely to occur in the prior austenitic condition at elevated temperatures. As subsequent transformation to ferrite-pearlite microstructures obliterates these boundaries, S segregation to ferrite boundaries is less likely, particularly at the low S concentration (20 ppm) of the X70 steel investigated. The low incidence of intergranular cracking in the present steel is consistent with this reasoning. Nevertheless, higher sulphur contents are generally considered to promote intergranular cracking by weakening the grain boundaries. This effect is likely to account for the dominance of intergranular cracking reported for API-5L-X46 and ASMEA106 grade B steels in Refs. [19, 22], which contained sulphur contents of 320 ppm and 90 ppm, respectively. Although analysis of grain boundary chemistry was not undertaken in the present study, the dominance of transgranular cracking for all of the microstructures studied 
is consistent with the relatively low S content of the steel, which is expected to reduce the concentration of solute (uncombined) $\mathrm{S}$ that is available to segregate to grain boundaries.

\subsection{Crack propagation planes}

The observation of dominant fracture along slip planes in the present study is in general agreement with previous HICC investigations on iron alloys, as discussed below.

In early studies relying on the observation of the dislocation etch-pit patterns around hydrogen-induced cracks in Fe-Si single crystals, Robertson and co-workers [35, 36] reported transgranular crack propagation along the typical $\{001\}$ cleavage planes. On the other hand, using X-ray trace analysis during HICC testing of several grades of purified iron, Bernstein observed transgranular cracking along the $\{110\}$ and $\{112\}$ slip planes while the $\{001\}$ cleavage planes were absent [37]. In order to resolve the apparent contradiction between Refs [35, 36] and [37], Nakasato and Bernstein [38] performed a systematic study of HICC in purified iron and a series of Fe-Si alloys (with Si content up to 3\%). X-ray trace analysis revealed a complete transition from slip plane cracking (at $0 \% \mathrm{Si}$ ) to cleavage plane cracking (at 3\% Si) with increasing silicon content; a mixture of both modes was obtained at $0.7 \% \mathrm{Si}$. Consequently, it was suggested that transgranular cracking in iron alloys is more likely to occur along slip planes rather than the $\{001\}$ cleavage planes. Therefore the present results are also in qualitative agreement with Refs [18, 19, 22], wherein a combination of $\{001\}$, $\{110\},\{112\}$ and $\{123\}$ crack propagation planes (no fractions given) was observed following extensive EBSD studies of HICC in API-5L-X46 pipeline steel with a ferritepearlite microstructure.

The significance of delineating the dominant transgranular crack propagation plane can be better understood by correlating it to the potential mechanisms for HICC. It has been proposed that the crack propagation plane is mainly a function of the intrinsic toughness of the iron alloy lattice [38]: (i) cleavage cracking is promoted by low intrinsic toughness such that the internal molecular hydrogen mainly acts as a local stress raiser which can initiate crack nucleation on the $\{001\}$ planes; and (ii) slip-based cracking is associated with high intrinsic toughness as the internal hydrogen pressure tends to induce highly localised slip on slip planes which can instigate cracking along the most highly stressed slip planes. However, rather than intrinsic toughness, the local microstructure in the stress-concentrated zone ahead of the crack tip is likely to influence the cracking mechanism [9], as discussed earlier. The 
concurrent operation of these two mechanisms leads to a combination of cleavage and slipbased cracking, as observed in the present study. Similar trends were observed for the crack propagation planes in the BFP, FGB and EFP microstructures (Table 3) despite their different phases, grain sizes and shapes.

\section{Conclusions}

Hydrogen-induced cold cracking and blistering in hydrogen-charged X70 steel was found to be highly dependent on microstructure, particularly from the viewpoint of crack initiation, but the dominant macroscopic plane of crack propagation was parallel to the rolling plane in all cases. Crack initiation sites were predominantly coarse inclusions, mainly oxides, and ferrite-pearlite interfaces. These sites provide strong traps where hydrogen can accumulate until it reaches the critical hydrogen concentration for initiation of cracking. At a microstructural level, crack propagation was found to be partly intergranular, particularly for the BFP microstructure but, in general, it was transgranular and mostly along slip planes of the ferrite grains.

Other specific conclusions are as follows.

- The hydrogen-induced cracks largely propagated parallel to the rolling plane because of structural anisotropy arising from the essentially plane strain deformation conditions of the hot rolling process.

- The crack plane was not found to be related to a preferred ferrite grain orientation.

- Deviations from the planar crack morphology became more prominent with lengthy high temperature heat treatments that coarsened the ferrite grains and attenuated the effects of rolling.

- The onset of cracking and blistering was also retarded by these post-rolling treatments and also by microstructures that had a high density of reversible traps for hydrogen.

- EBSD mapping confirmed the dominance of transgranular cracking with the propagation plane being $\{001\}$ cleavage planes or the $\{110\},\{112\}$ and $\{123\}$ slip planes. 
- Slip-based cracking was found to be dominant over cleavage cracking for all of the microstructures examined.

\section{References}

[1] Asahi H, Hirakami D, Yamasaki S. Hydrogen trapping behavior in Vanadium-added steel. ISIJ Int. 2003;43:527-33.

[2] Komazaki S-i, Koyama A, Misawa T. Effect of morphology of copper precipitation particles on hydrogen embrittlement behavior in Cu-added ultra low carbon steel. Mater Trans. 2002;43:2213-8.

[3] Wei F-G, Hara T, Tsuchida T, Tsuzaki K. Hydrogen trapping in quenched and tempered 0.42C-0.30Ti steel containing bimodally dispersed TiC particles. ISIJ Int. 2003;43:539-47.

[4] Yokota T, Shiraga T. Evaluation of hydrogen content trapped by vanadium precipitates in a steel. ISIJ Int. 2003;43:534-8.

[5] Zhao M-C, Tang B, Shan Y-Y, Yang K. Role of microstructure on sulfide stress cracking of oil and gas pipeline steels. Metall Mater Trans A. 2003;34:1089-96.

[6] Thomas RS, Scully J, Gangloff R. Internal hydrogen embrittlement of ultrahigh-strength AERMET 100 steel. Metall Mater Trans A. 2003;34:327-44.

[7] Yamaguchi T, Nagumo M. Simulation of hydrogen thermal desorption under reversible trapping by lattice defects. ISIJ Int. 2003;43:514-9.

[8] Fellows JA, Boyer HE. Metals handbook, Vol. 9, Fractography and atlas of fractographs. $8^{\text {th }}$ ed ed. Metals Park (Ohio): American Society for Metals; 1974.

[9] Beachem CD. A new model for hydrogen-assisted cracking (hydrogen “embrittlement”). Metall Trans. 1972;3:441-55.

[10] Ren XC, Zhou QJ, Shan GB, Chu WY, Li JX, Su YJ, et al. A nucleation mechanism of hydrogen blister in metals and alloys. Metall Mater Trans A. 2008;39:87-97.

[11] Dong CF, Liu ZY, Li XG, Cheng YF. Effects of hydrogen-charging on the susceptibility of X100 pipeline steel to hydrogen-induced cracking. Int J Hydrogen Energy. 2009;34:987984.

[12] Elboujdaini M, Revie RW. Metallurgical factors in stress corrosion cracking (SCC) and hydrogen-induced cracking (HIC). J Solid State Electrochem. 2009;13:1091-9.

[13] Jin TY, Liu ZY, Cheng YF. Effect of non-metallic inclusions on hydrogen-induced cracking of API5L X100 steel. Int J Hydrogen Energy. 2010;35:8014-21.

[14] Xue HB, Cheng YF. Characterization of inclusions of X80 pipeline steel and its correlation with hydrogen-induced cracking. Corros Sci. 2011;53:1201-8.

[15] Mohtadi-Bonab MA, Szpunar JA, Collins L, Stankievech R. Evaluation of hydrogen induced cracking behavior of API X70 pipeline steel at different heat treatments. Int J Hydrogen Energy. 2014;39:6076-88.

[16] Dunne DP, Hejazi D, Saleh AA, Haq AJ, Calka A, Pereloma EV. Investigation of the effect of electrolytic hydrogen charging of X70 steel: I. The effect of microstructure on hydrogen induced cold cracking and blistering. Submitted for publication. 2015.

[17] Brandon DG. The structure of high-angle grain boundaries. Acta Metall. 1966;14:147984.

[18] Venegas V, Caleyo F, González JL, Baudin T, Hallen JM, Penelle R. EBSD study of hydrogen-induced cracking in API-5L-X46 pipeline steel. Scr Mater. 2005;52:147-52. 
[19] Venegas V, Caleyo F, Hallen JM, Baudin T, Penelle R. Role of crystallographic texture in hydrogen-induced cracking of low carbon steels for sour service piping. Metall Mater Trans A. 2007;38:1022-31.

[20] Kim S, Marrow TJ. Application of electron backscattered diffraction to cleavage fracture in duplex stainless steel. Scr Mater. 1999;40:1395-400.

[21] Nohava J, Haušild P, Karlík M, Bompard P. Electron backscattering diffraction analysis of secondary cleavage cracks in a reactor pressure vessel steel. Mater Charact. 2002;49:2117.

[22] Venegas V, Caleyo F, Baudin T, Hallen JM, Penelle R. Role of microtexture in the interaction and coalescence of hydrogen-induced cracks. Corros Sci. 2009;51:1140-5.

[23] Albarran JL, Martinez L, López HF. The sour gas susceptibility of an X-80 steel for oil and gas transport. Scr Mater. 1998;38:749-55.

[24] Lee H-L, Lap-Ip Chan S. Hydrogen embrittlement of AISI 4130 steel with an alternate ferrite/pearlite banded structure. Mater Sci Eng A. 1991;142:193-201.

[25] Ren X, Chu W, Li J, Su Y, Qiao L. The effects of inclusions and second phase particles on hydrogen-induced blistering in iron. Mater Chem Phys. 2008;107:231-5.

[26] Dong CF, Li XG, Liu ZY, Zhang YR. Hydrogen-induced cracking and healing behaviour of X70 steel. J Alloys Compd. 2009;484:966-72.

[27] Watanabe T. The impact of grain boundary character distribution on fracture in polycrystals. Mater Sci Eng A. 1994;176:39-49.

[28] Beidokhti B, Dolati A, Koukabi AH. Effects of alloying elements and microstructure on the susceptibility of the welded HSLA steel to hydrogen-induced cracking and sulfide stress cracking. Mater Sci Eng A. 2009;507:167-73.

[29] Park GT, Koh SU, Jung HG, Kim KY. Effect of microstructure on the hydrogen trapping efficiency and hydrogen induced cracking of linepipe steel. Corros Sci. 2008;50:1865-71.

[30] Pressouyre GM. Trap theory of hydrogen embrittlement. Acta Metall. 1980;28:895-911.

[31] Evaluation of pipeline and pressure vessel steels for resistance to hydrogen-induced cracking. NACE TM0284-2003: NACE International; 2003.

[32] Dunne DP, Dunlea RL. Grain shape anisotropy in cold-rolled and recrystallised aluminium-killed steel. Met Forum. 1978;1:156.

[33] Arafin MA, Szpunar JA. A novel microstructure - Grain boundary character based integrated modeling approach of intergranular stress corrosion crack propagation in polycrystalline materials. Comput Mater Sci. 2010;47:890-900.

[34] Bruemmer SM, Jones RH, Thomas MT, Baer DR. Fracture mode transition of iron in hydrogen as a function of grain boundary sulfur. Scr Metall. 1980;14:137-41.

[35] Gell M, Robertson WD. An analysis of plastic deformation around stationary cleavage cracks. Acta Metall. 1966;14:481-90.

[36] Tetelman AS, Robertson WD. Direct observation and analysis of crack propagation in iron-3\% silicon single crystals. Acta Metall. 1963;11:415-26.

[37] Bernstein IM. Hydrogen-induced cracking in iron: Morphology and crack path dependence. Metall Trans. 1970;1:3143-50.

[38] Nakasato F, Bernstein IM. Crystallographic and fractographic studies of hydrogeninduced cracking in purified iron and iron- silicon alloys. Metall Trans A. 1978;9:1317-26. 
Part II Tables

Table 2. Crack severity ratios for X70 samples measured from the RD-ND (Section A) and TD-ND (Section B) sections [8]. CSR is the crack sensitivity ratio; CLR is the crack length ratio; and CTR is the crack thickness ratio. BFP refers to the banded ferrite pearlite microstructure; FGB denotes the ferrite-granular bainite structure of the transfer bar (TB); and EFP represents the equiaxed ferrite-pearlite structure with an average ferrite grain size of $14 \mu \mathrm{m}$.

\begin{tabular}{|c|c|c|c|c|c|c|}
\hline \multirow{2}{*}{ Microstructure } & \multicolumn{2}{|c|}{ CSR (\%) } & \multicolumn{2}{c|}{ CLR (\%) } & \multicolumn{2}{c|}{ CTR (\%) } \\
\cline { 2 - 7 } & Section A & Section B & Section A & Section B & Section A & Section B \\
\hline BFP & 3.1 & 6.2 & 25.9 & 25.2 & 163.2 & 221.6 \\
\hline EFP $(14 \mu \mathrm{m})$ & 2.2 & 0.2 & 17.3 & 2.7 & 108.2 & 39.1 \\
\hline FGB & 5.4 & 3.7 & 14.8 & 10.0 & 130.1 & 105.9 \\
\hline
\end{tabular}

Table 1. Fractions of various crack planes for transgranular cracking of the different X70 microstructures.

\begin{tabular}{|c|c|c|c|c|}
\hline Microstructure & $\{001\}$ & $\{110\}$ & $\{112\}$ & $\{123\}$ \\
\hline BFP & 0.22 & 0.33 & 0.28 & 0.17 \\
\hline EFP(14 $\mu \mathrm{m})$ & 0.10 & 0.20 & 0.50 & 0.20 \\
\hline FGB & 0.30 & 0.20 & 0.26 & 0.24 \\
\hline
\end{tabular}



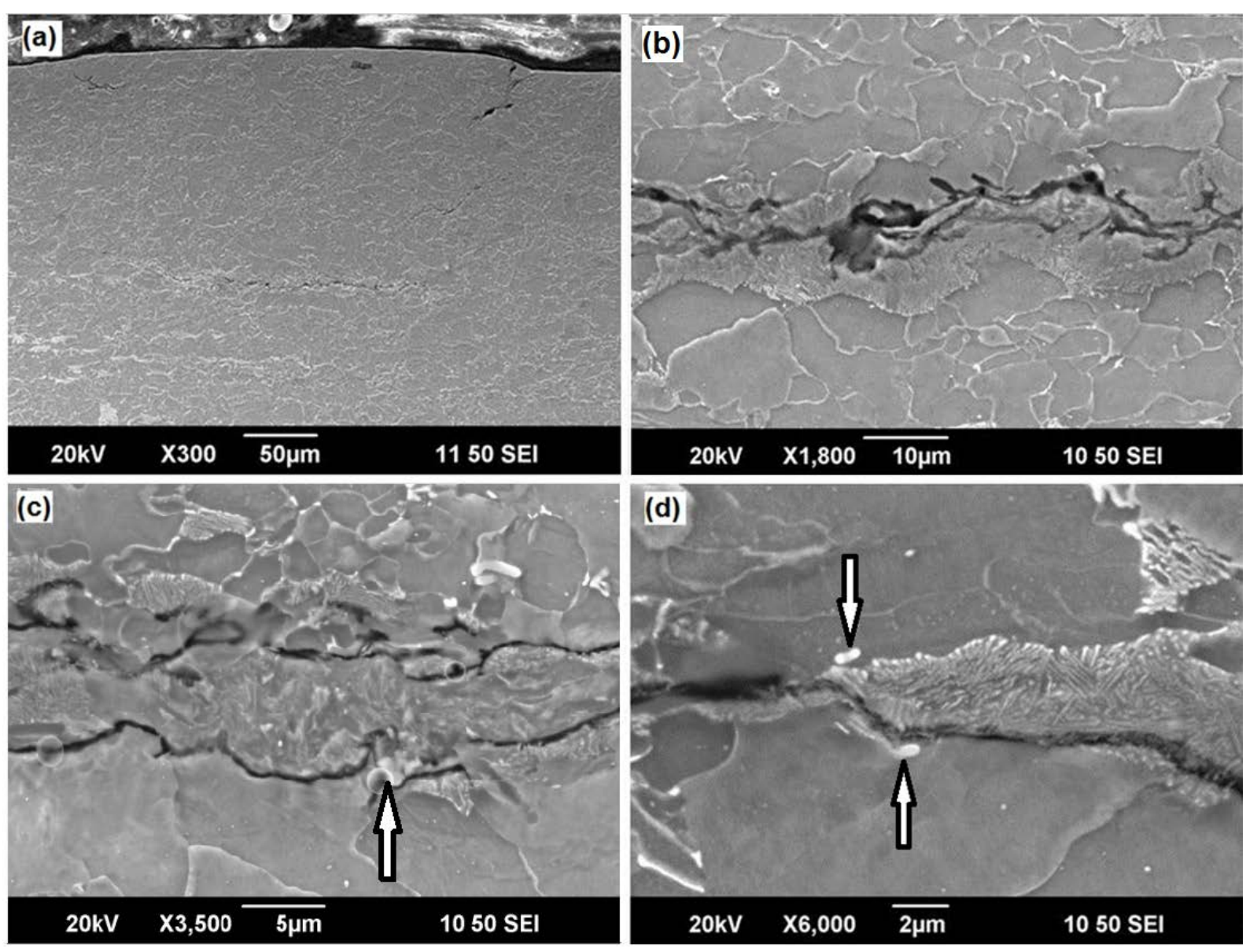

Figure 1. SEM micrographs from the RD-ND cross-section of the BFP microstructure after 3 hours of hydrogen charging: (a) general view showing the raised surface due to the formation of a blister and (b, c and d) details of cracking and the microstructures below the blister, shown at different magnifications). Arrows indicate precipitate particles. 

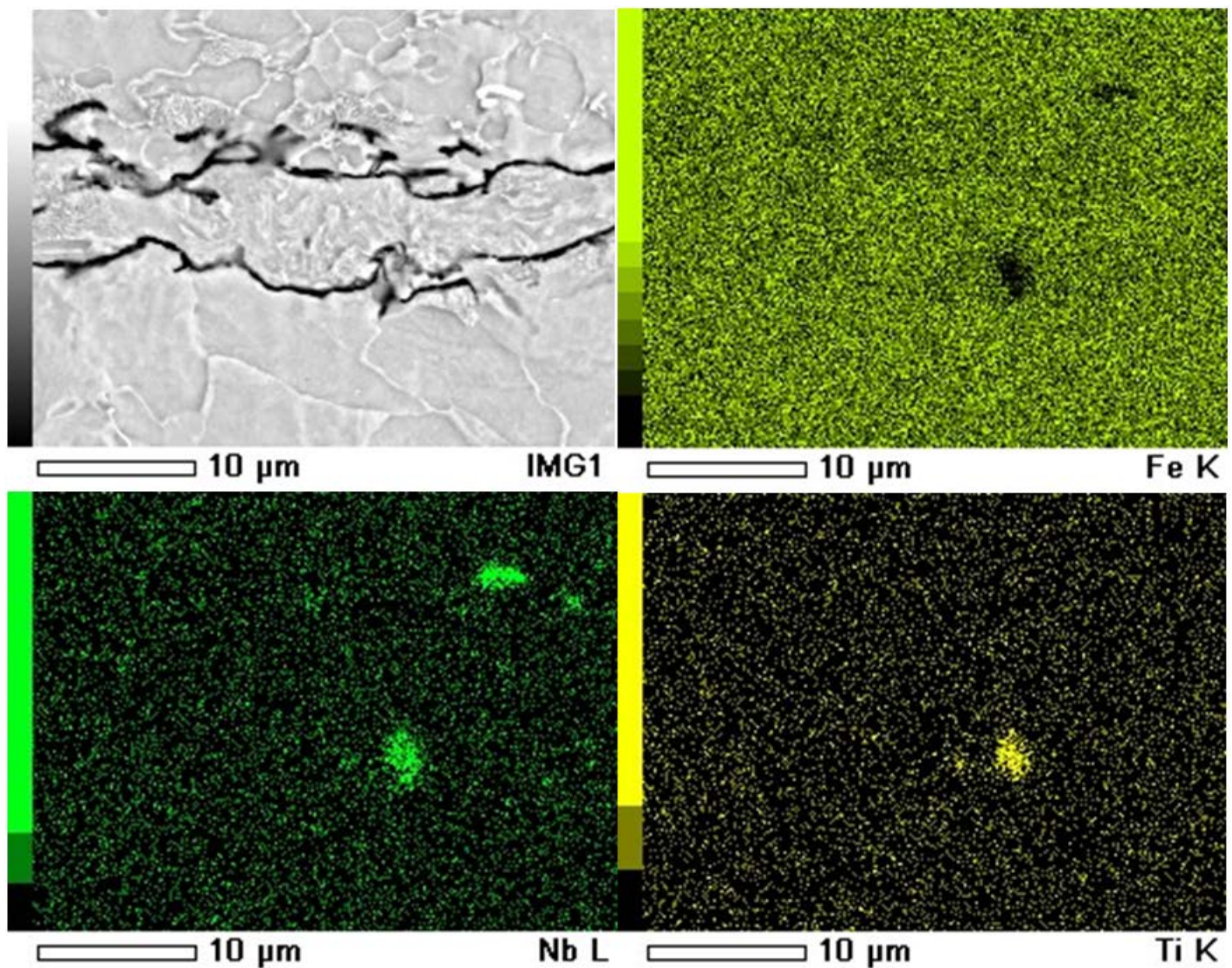

Figure 2. Elemental maps corresponding to Figure 1(c) showing that the particle lying along the crack path is Nb- and Ti-rich. 

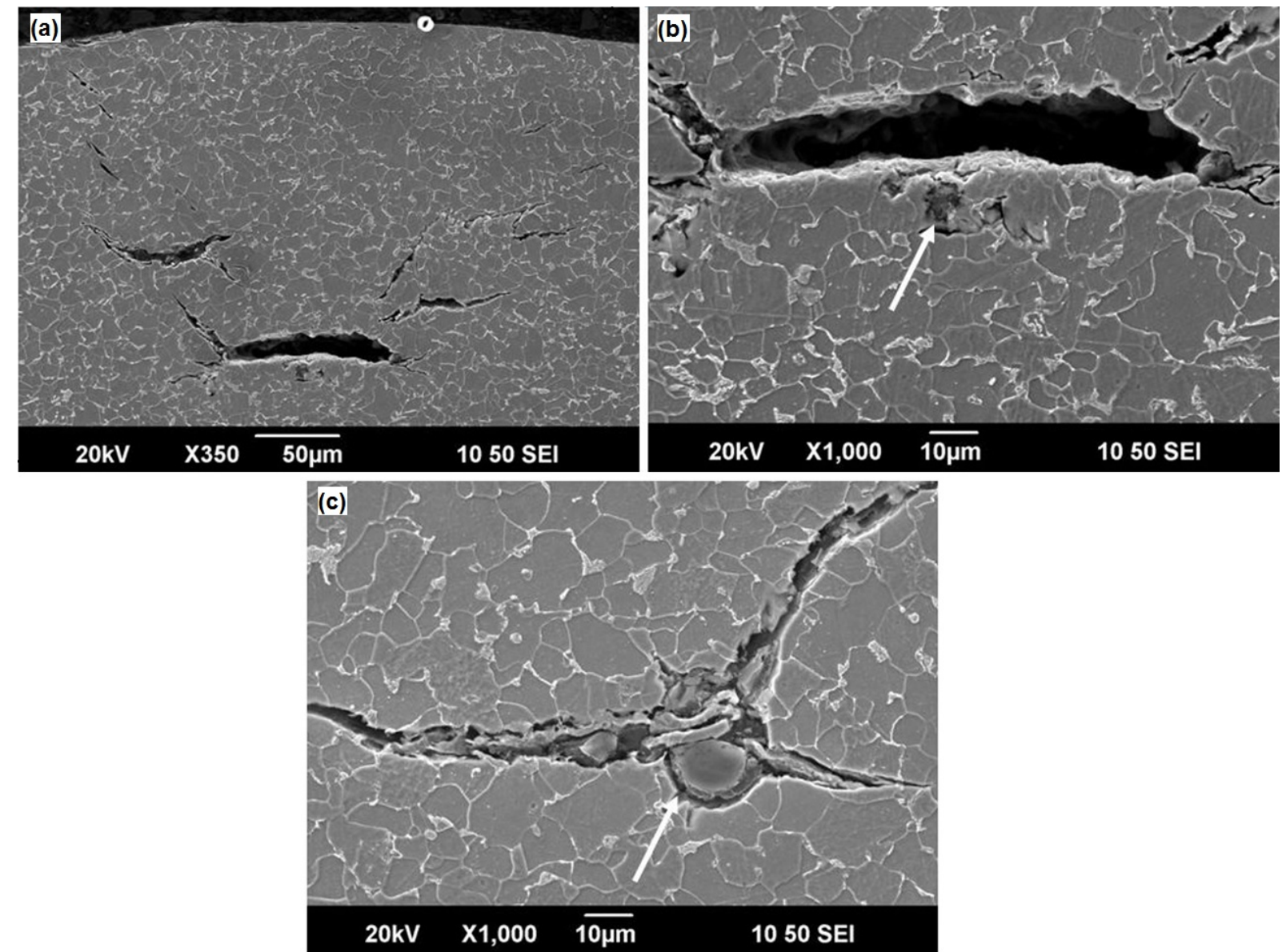

Figure 3. SEM micrographs from the RD-ND cross-section of the EFP microstructure after 3 hours of hydrogen charging: (a) general cross-sectional view showing a large blister and underlying cracks; (b) higher magnification image of the large void, with crack extensions and a large inclusion also associated with cracking (arrowed); and (c) an inclusion (arrowed) associated with a branching crack. 

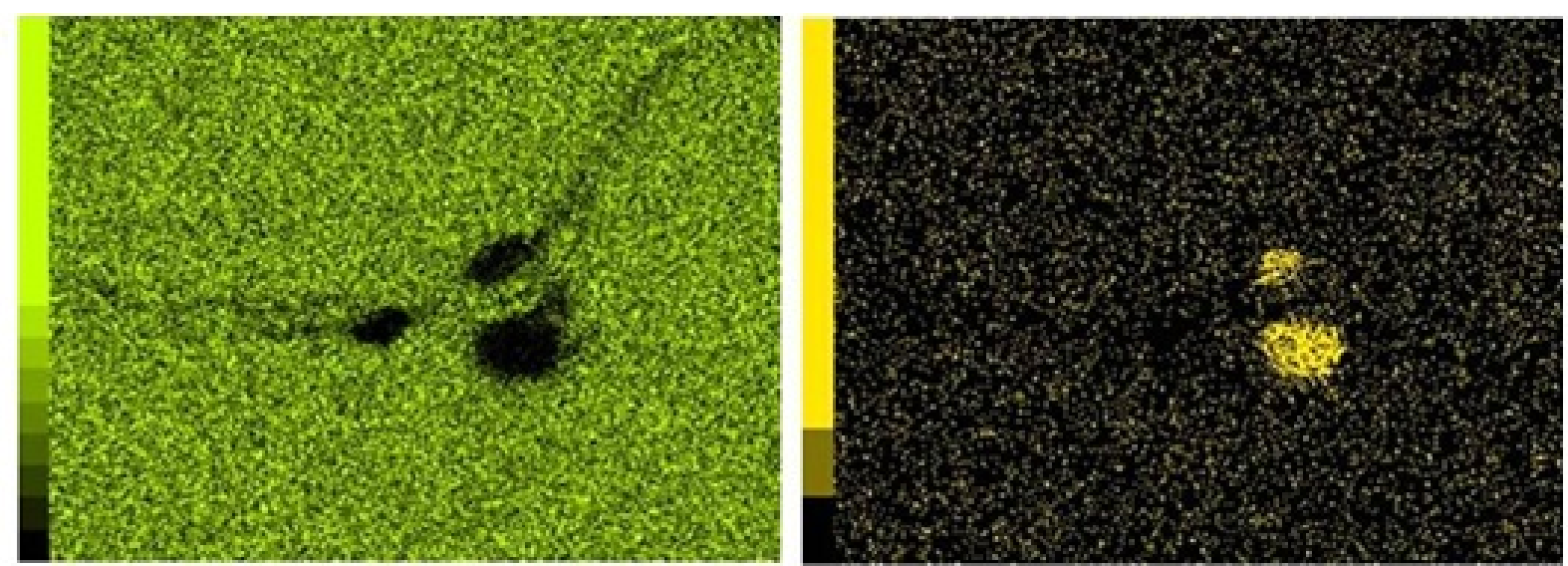

$30 \mu \mathrm{m}$

$\mathrm{Fe} \mathrm{K}$

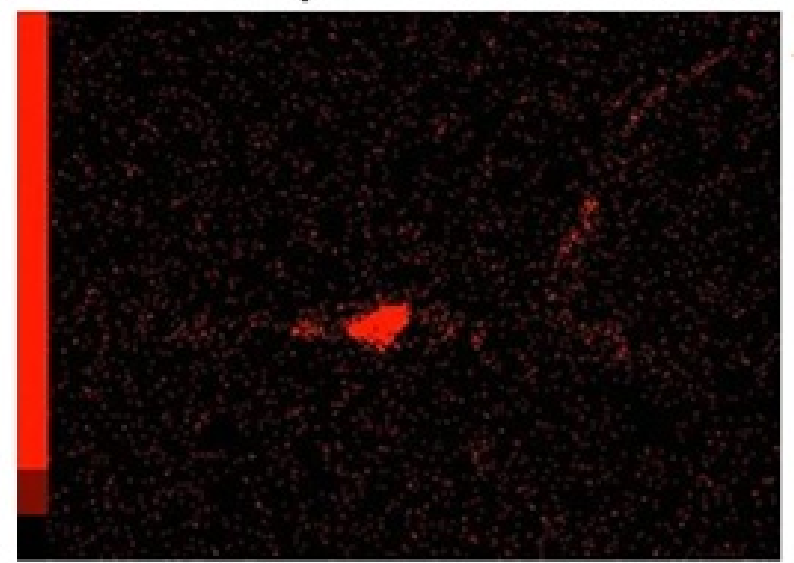

$30 \mu \mathrm{m}$

$\mathrm{C} \mathrm{K}$

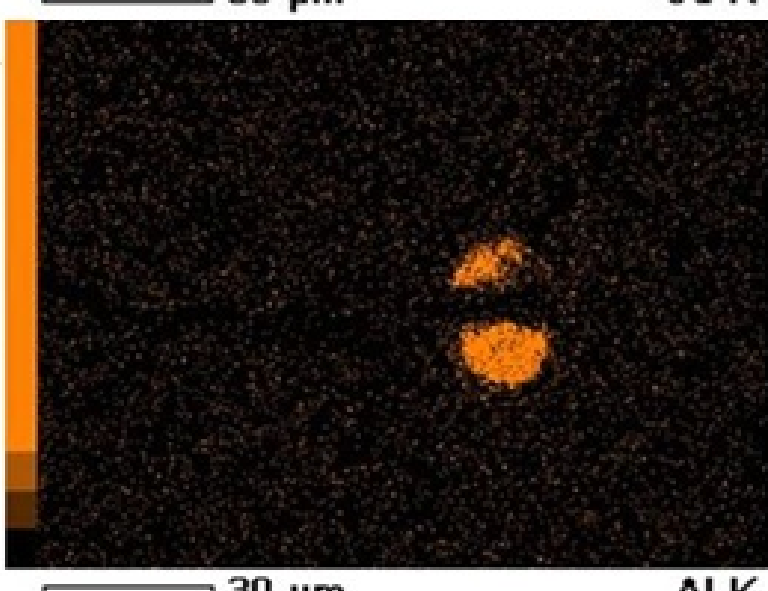

$30 \mu \mathrm{m}$

Al K

Figure 4. Elemental mapping for three inclusions identified in Figure 3(c), showing that $\mathrm{Al}$ and $\mathrm{Ca}$ are the main metallic elements of two of the inclusions. 

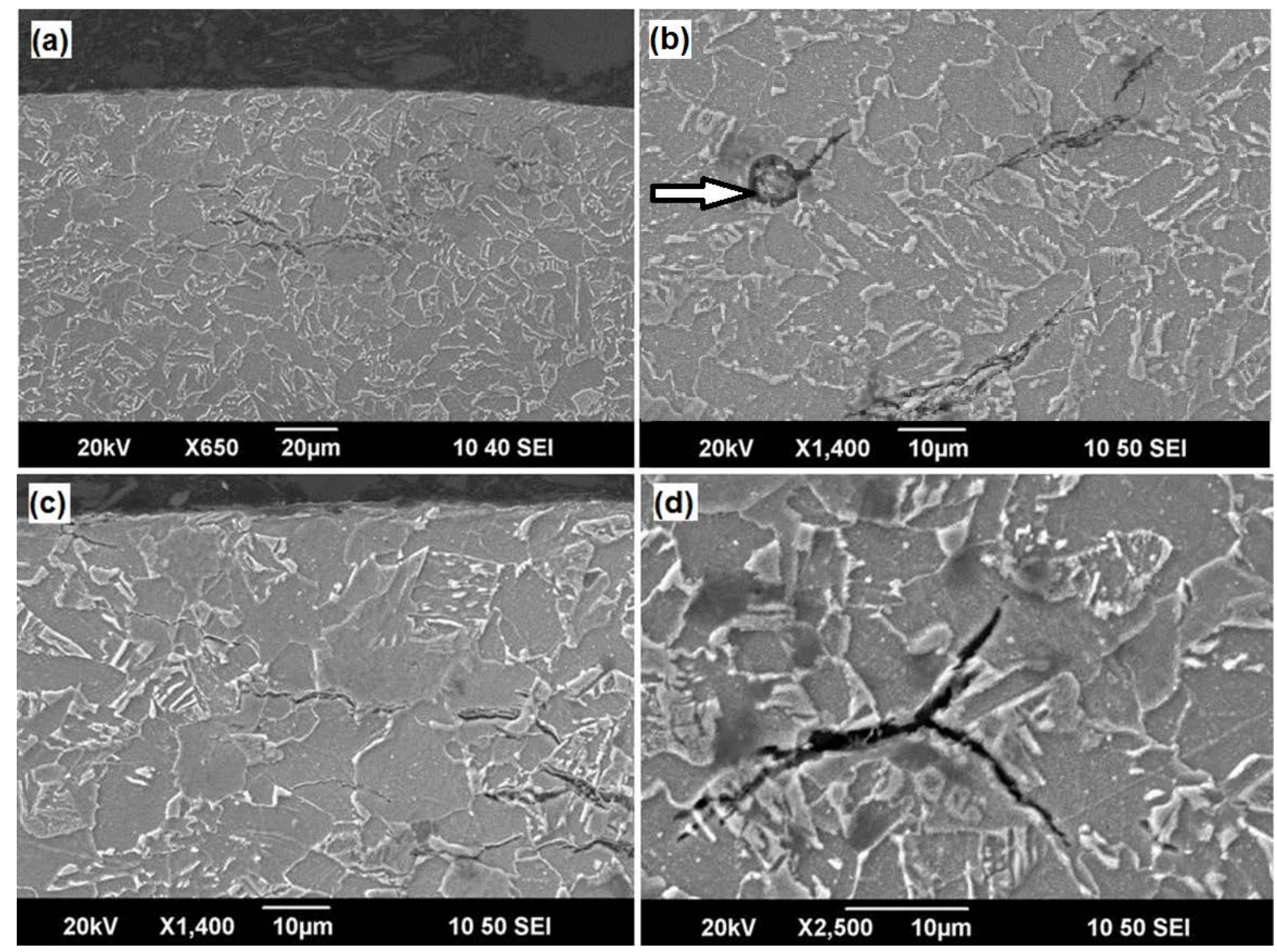

Figure 5. SEM micrographs from the RD-ND cross-section of the FGB microstructure after 17 hours of hydrogen charging: (a) low magnification image showing a small blister and underlying cracks; and (b, c and d) hydrogen induced cracks at higher magnifications. Note the branched nature of the cracking in (d). 

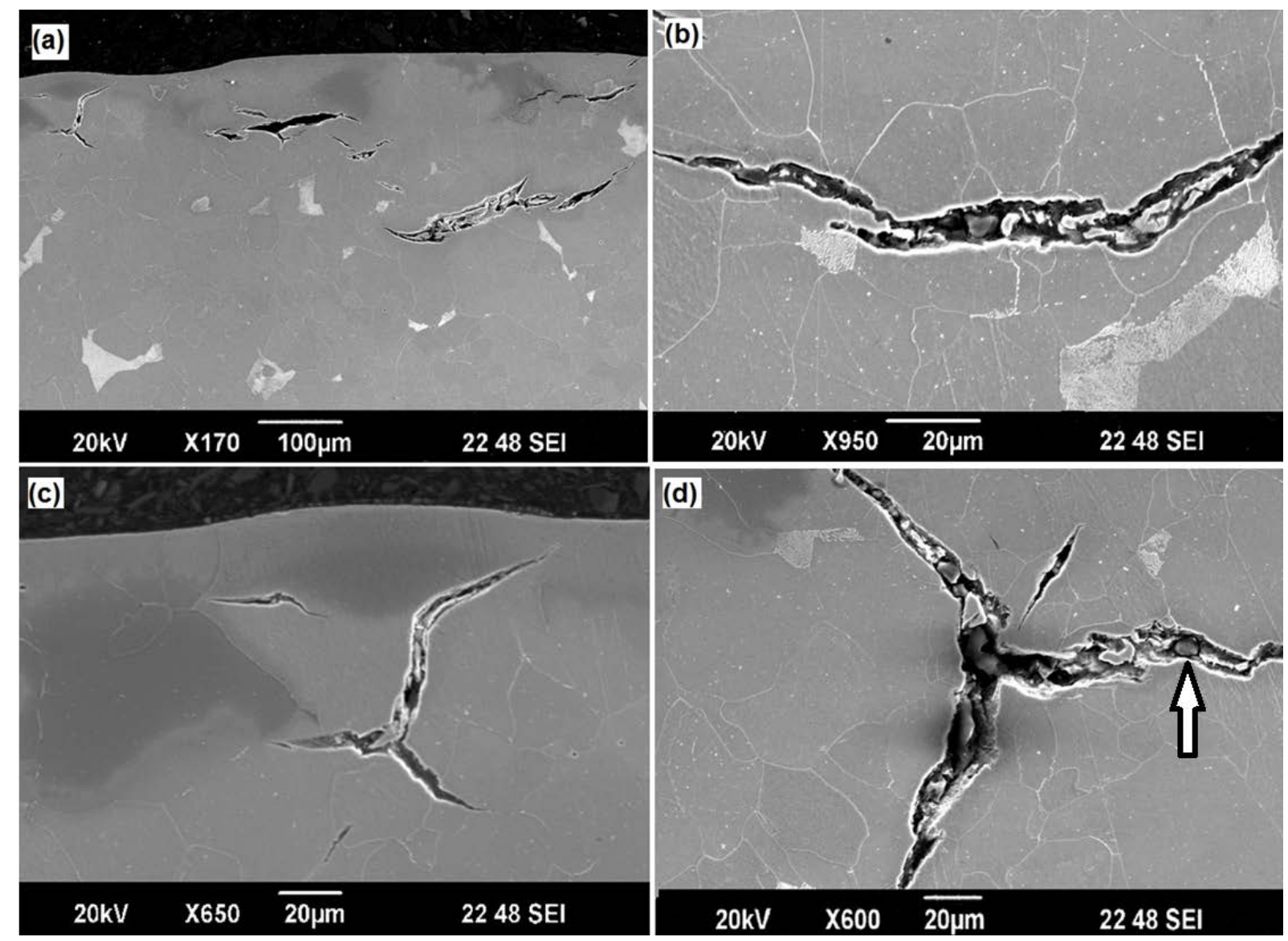

Figure 6. SEM micrographs from the RD-ND cross-section of the EFP microstructure with $46 \mu \mathrm{m}$ average ferrite grain size, after 3 hours of hydrogen charging: (a) general view showing cracks close to a surface blister; (b) higher magnification view of a crack; and (c, d) branched intergranular cracks. The arrow in (d) shows an inclusion located within a crack. 


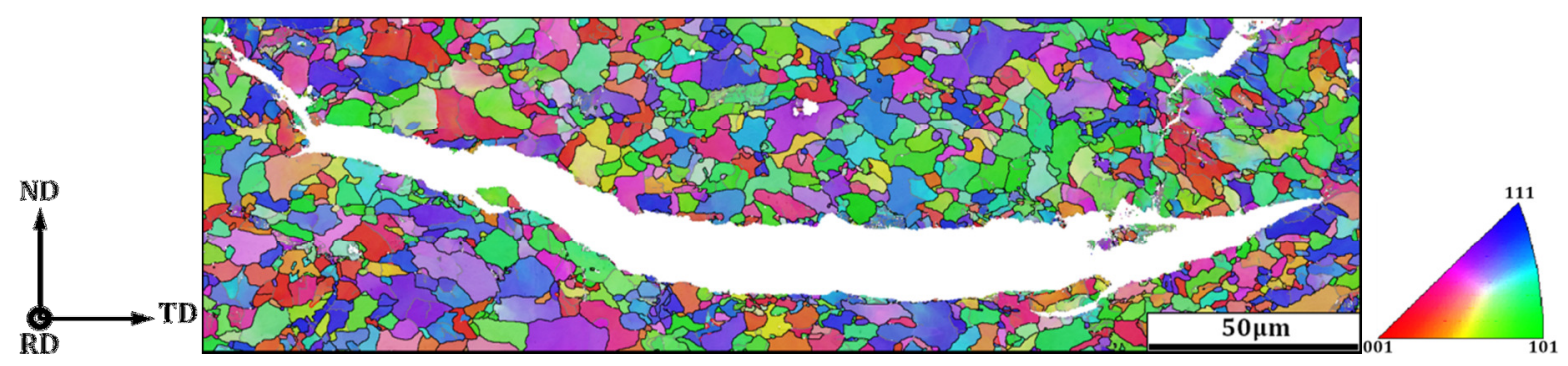

(a)

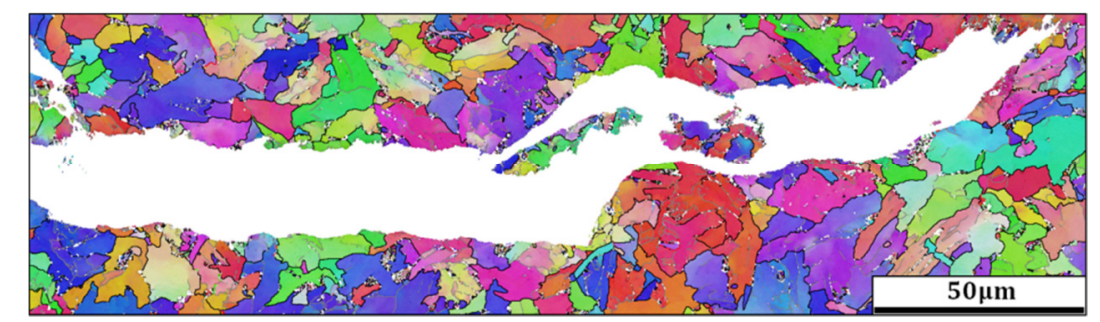

(b)

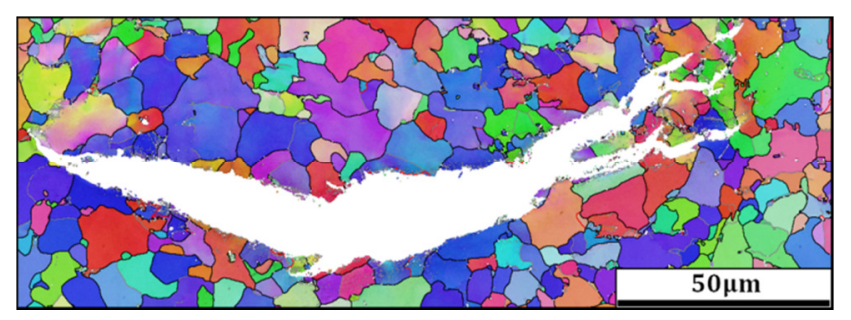

(c)

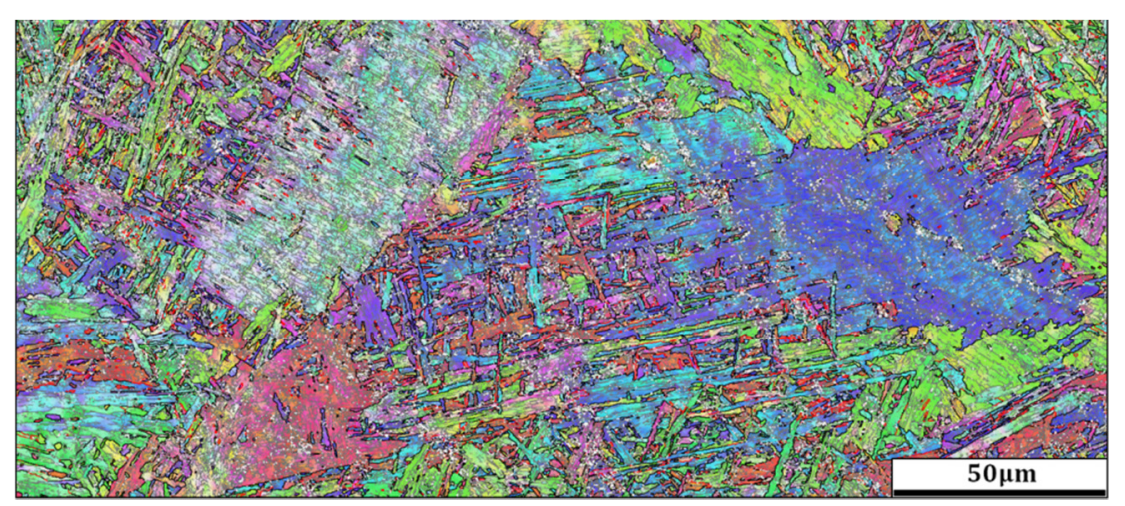

(d)

Figure 7. Inverse pole figure maps of the (a) BFP, (b) FGB, (c) EFP and (d) BF microstructures. LAGB = grey, HAGB = black. 


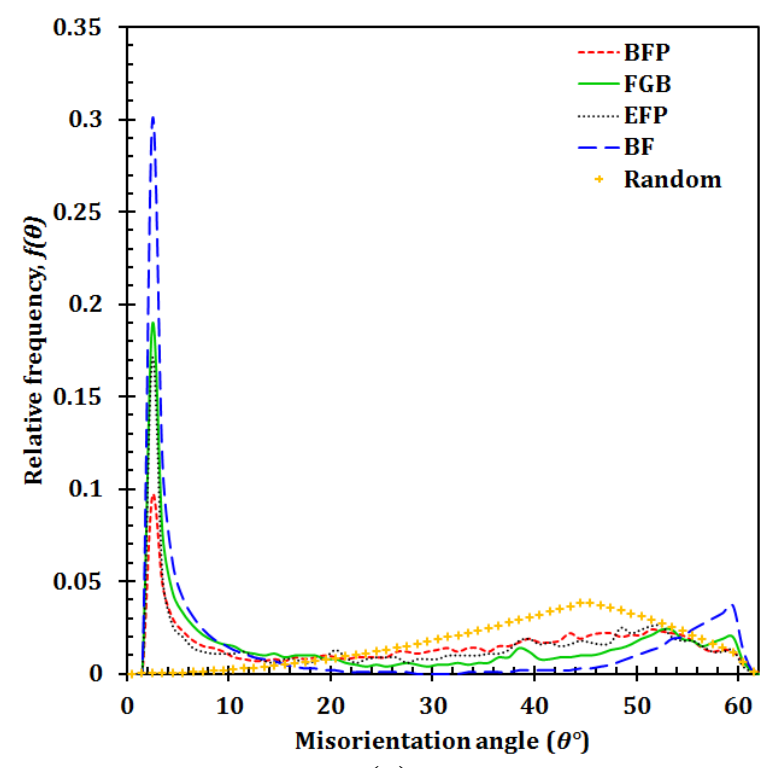

(a)

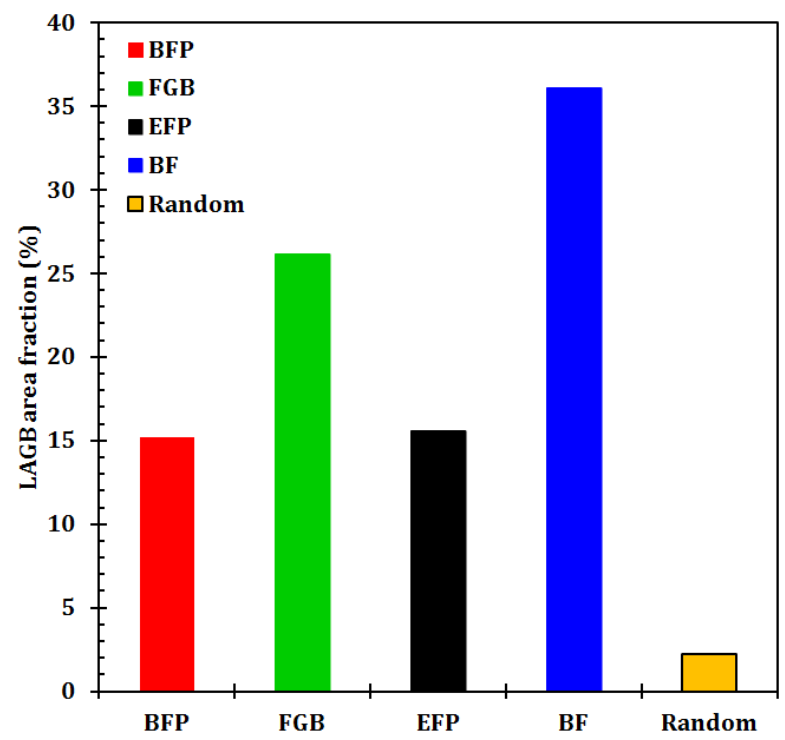

(b)

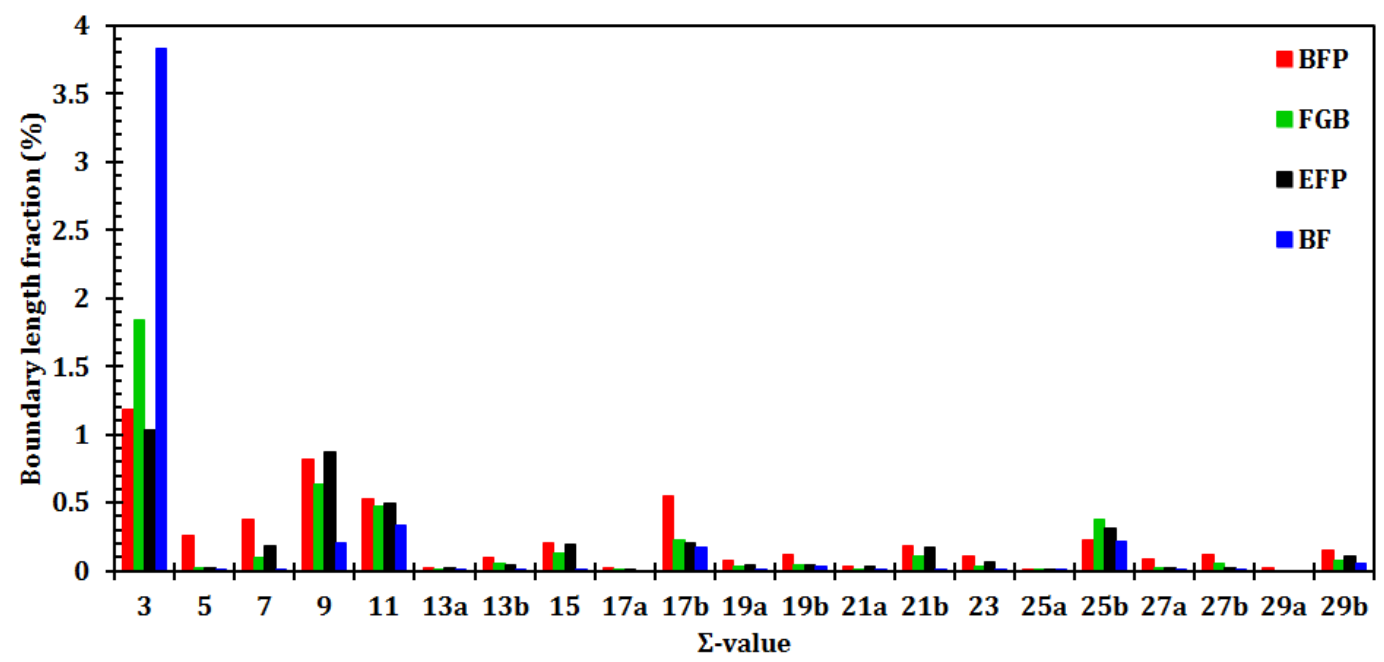

(c)

Figure 8. (a) Misorientation distributions for the four microstructures investigated; (b) LAGB area fractions; (c) length fractions of CSL boundaries. 


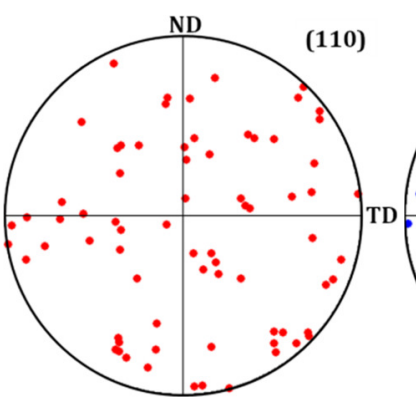

(a)

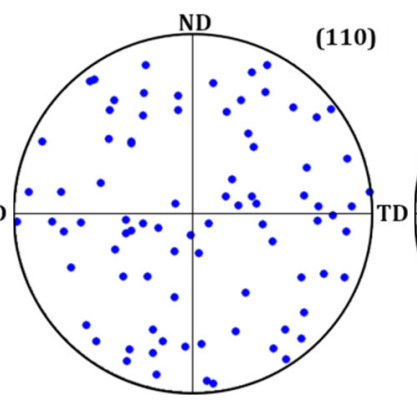

(b)

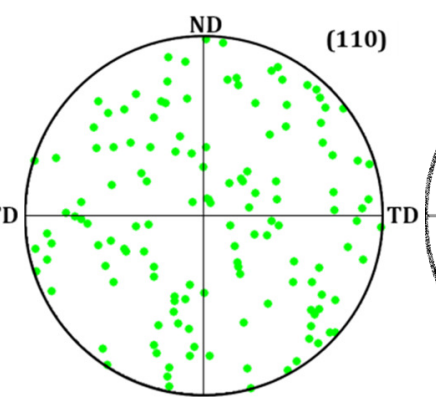

(c)

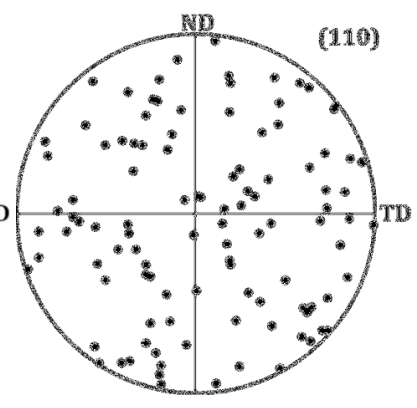

(d)

Figure 9. (110) pole figures depicting the orientations of the grains for which (a) $\{001\}$, (b) $\{110\}$, (c) $\{112\}$ and (d) $\{123\}$ crack propagation planes were observed in all three microstructures investigated.

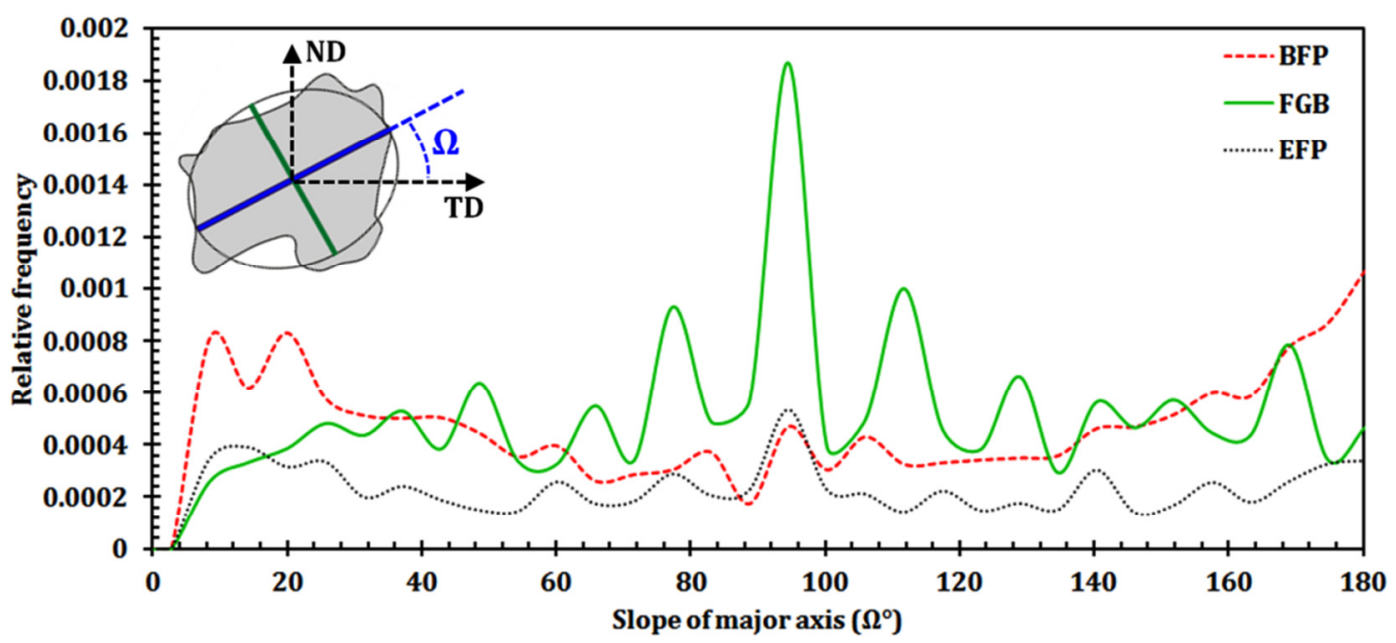

Figure 10. Distributions of the slope angle $(\Omega)$ of the major fitted ellipse axis in the TD-ND cross-section for the BFP, FGB and EFP microstructures. 